\title{
Two-Year Follow-Up of Cognitive Functions in Schizophrenia Spectrum Disorders of Adolescent Patients Treated with Electroconvulsive Therapy
}

\author{
Elena de la Serna, Ph.D.,, ${ }^{1,2}$ Itziar Flamarique, M.D., Ph.D., ${ }^{2}$ Josefina Castro-Fornieles, M.D., Ph.D., ${ }^{1-4}$ \\ Alexandre Pons, M.D., Ph.D., ${ }^{1,5,6}$ Olga Puig, Ph.D., 2 Susana Andrés-Perpiña, Ph.D., ${ }^{1-3}$ \\ Luisa Lázaro, Ph.D., ${ }^{1-4}$ Juan Miguel Garrido, M.D., Ph.D., ${ }^{6}$ \\ Miguel Bernardo, M.D., Ph.D., ${ }^{1,3-6}$ and Inmaculada Baeza, M.D., Ph.D.1-3,5
}

\begin{abstract}
Objective: The aim of the current study was to investigate the long-term cognitive effects of electroconvulsive therapy (ECT) in a sample of adolescent patients in whom schizophrenia spectrum disorders were diagnosed.

Methods: The sample was composed of nine adolescent subjects in whom schizophrenia or schizoaffective disorder was diagnosed according to DSM-IV-TR criteria on whom ECT was conducted (ECT group) and nine adolescent subjects matched by age, socioeconomic status, and diagnostic and Positive and Negative Syndrome Scale (PANSS) total score at baseline on whom ECT was not conducted (NECT group). Clinical and neuropsychological assessments were carried out at baseline before ECT treatment and at 2-year follow-up.

Results: Significant differences were found between groups in the number of unsuccessful medication trials. No statistically significant differences were found between the ECT group and the NECT group in either severity as assessed by the PANSS, or in any cognitive variables at baseline. At follow-up, both groups showed significant improvement in clinical variables (subscales of positive, general, and total scores of PANSS and Clinical Global Impressions-Improvement). In the cognitive assessment at follow-up, significant improvement was found in both groups in the semantic category of verbal fluency task and digits forward. However, no significant differences were found between groups in any clinical or cognitive variable at follow-up. Repeated measures analysis found no significant interaction of time $\times$ group in any clinical or neuropsychological measures.

Conclusions: The current study showed no significant differences in change over time in clinical or neuropsychological variables between the ECT group and the NECT group at 2-year follow-up. Thus, ECT did not show any negative influence on long-term neuropsychological variables in our sample.
\end{abstract}

\section{Introduction}

$\mathbf{E}$ LECTROCONVULSIVE THERAPY (ECT) HAS been demonstrated to be a safe and effective procedure in adult patients. There is also evidence that ECT is useful in children and adolescents with certain severe psychiatric disorders who fail to respond to pharmacotherapy or require a quick response due to life-threatening symptoms (Ghaziuddin et al. 1996; Moise and Petrides 1996; Baeza et al. 2010). Variable rates of improvement or remission of symptoms by the end of the course of ECT have been observed:
$63 \%$ for patients with depression, $80 \%$ in patients with mania, and $42 \%$ for those with schizophrenia (Rey and Walter 1997). A relatively low incidence of relevant adverse events in adolescents has also been described (Taieb et al. 2002; Bloch et al. 2008).

In adults, short-term follow-up studies have shown memory impairments in patients treated with ECT (for a review, see RamiGonzalez et al. 2001; Ingram et al. 2008). Specifically, studies with patients with different mood disorders have found difficulties encoding new information and in long delay verbal recall after ECT treatment (Steif et al. 1986; Rami-Gonzalez et al. 2003b) as well as

\footnotetext{
${ }^{1}$ Centro de Investigación Biomédica en Red de Salud Mental, Barcelona, Spain.

${ }^{2}$ Department of Child and Adolescent Psychiatry and Psychology, Institut Clinic de Neurociències, Hospital Clínic Universitari, Barcelona, Spain.

${ }^{3}$ Institut d'Investigació Biomèdica August Pi i Sunyer, Barcelona, Spain.

${ }^{4}$ Department of Psychiatry and Clinical Psychology, University of Barcelona, Barcelona, Spain.

${ }^{5}$ Programa Esquizofrènia Clínic, Barcelona, Spain.

${ }^{6}$ Department of Psychiatry, Institut Clínic de Neurociències, Hospital Clínic Universitari, Barcelona, Spain.

This study was supported by a grant from ISCIII (Ministry of Health, Spain) and a grant from Centro de Investigación Biomédica en Red de Salud Mental, CIBER-SAM. These institutions had no further role in the study design; in the collection, analysis, and interpretation of data; in the writing of the report; or in the decision to submit the article for publication.
} 
retrograde amnesia for remote events (Squire 1977; Lisanby et al. 2000; Ingram et al. 2008). Moreover, electrode position, energy, and type of current have been related with the degree of cognitive impairments. Specifically, some of them (Weeks et al. 1980; Squire and Chace 1996; Sackeim et al. 2008) have found that unilateral right positions have less severe cognitive effects than bilateral positions, which support previous review studies (Squire 1977; Calev et al. 1995; Squire and Chace 1996). Sackeim et al. (2008) in a double-blind study investigate the effects of different electrode placement (bilateral vs. right unilateral) and pulse width ( 0.3 vs. $1.5 \mathrm{~ms}$ ) and found that the ultrabrief right unilateral group had less cognitive side effects than the other groups. Regarding electrical dosage, Sackeim et al. (2000) compared different electrode position (bilateral vs. right unilateral) and electric dosage (50\% vs. $150 \%$ and $500 \%$ above the seizure threshold) and found that a high dosage result in a greater cognitive impairment. Most of these studies have also shown that both learning and retaining were totally recovered between a few weeks and 7 months after the ECT series (Weeks et al. 1980; Frith et al. 1983; Calev et al. 1991; Squire and Chace 1996). Moreover, Zervas et al. (1993) associated patient age in adults to the risk of short-term memory deficits in patients treated with ECT. Thus, the authors found more severe deficits in older patients for verbal and visuospatial anterograde and retrograde memory, thereby concluding that older patients were more vulnerable to cognitive effects of ECT.

A few studies have investigated other cognitive functions, most finding no differences between ECT and no-ECT groups of patients (Vothknecht et al. 2003; Rami et al. 2004). However, two casecontrol studies analyzing the effects of maintenance ECT found some impairments in verbal fluency (Rami-Gonzalez et al. 2003a) and speed of information processing (Tsourtos et al. 2007).

In adolescents, Ghaziuddin et al. (2000) reported a sample of 16 adolescents with mood disorder and administered a cognitive battery before the ECT treatment, 1 week after the last ECT session, and $\sim 8$ months after the last session. Results showed significant impairments in attention, verbal and visual delayed recall, and verbal fluency between the pretreatment evaluation and 1 week post-treatment assessment, which had disappeared at the second post-treatment assessment 8 months later.

Regarding long-term studies with a follow-up longer than 1 year, there are to our knowledge only three studies that have analyzed the cognitive effects of ECT in adult samples (Russell et al. 2003; Johanson et al. 2005; MacQueen et al. 2007). Johanson et al. (2005) analyzed the cognitive effects of ECT in 55 patients with depression who were followed up 20-24 years after the ECT treatment. Patients showed a slight impairment of working memory and verbal memory, but there was no control group against which to make a comparison. MacQueen et al. (2007) studied subjective and objective memory impairments in three samples of subjects matched for age and sex but not for clinical severity: A group of 20 patients with bipolar disorder treated with ECT, a group of 20 patients with bipolar disorder with no ECT treatment, and 20 healthy controls were followed up during 45 months. The authors concluded that the patients who received ECT had significantly lower scores in memory and verbal learning tests. Nevertheless, Russell et al. (2003) carried out a retrospective study of 43 patients with different diagnoses (depression, bipolar disorder, and schizoaffective disorder) who had received at least 1 year of maintenance ECT and found no significant differences in cognitive domains assessed with the MiniMental State Exam between baseline and follow-up evaluations.

Only one study has analyzed cognitive effects of ECT in a sample of adolescents with a long-term follow-up (Cohen et al.
2000). A sample of 10 adolescents in whom mood disorder was diagnosed were followed up until 3.5 years after the last ECT session and compared with 10 psychiatric comparison subjects. The authors found that adolescents treated with ECT did not show cognitive impairment at long-term follow-up in objective measures of cognitive function; nevertheless, they found a subjective memory impairment measured with the Squire's Subjective Memory Questionnaire in two subjects.

No follow-up studies have been carried out in relation to cognition in adolescents with schizophrenia spectrum disorder treated with ECT.

Thus, taking into account this lack of information from previous long-term studies in children and adolescents with schizophrenia spectrum disorder, the aim of the current study was to investigate the long-term cognitive effects of ECT in a sample of adolescent patients with these disorders. We hypothesized that no significant differences would be found in cognitive measures after 2-year follow-up between an ECT group and a no-ECT group.

\section{Methods}

\section{Subjects}

We included nine adolescent subjects aged between 13 and 18 ( $22 \%$ men), and in whom schizophrenia $(n=7)$ or schizoaffective disorder $(n=2)$ was diagnosed according to DSM-IV-TR criteria on whom ECT was conducted following the American Psychiatric Association (2001) and the American Academy of Child and Adolescent Psychiatry (AACAP) recommendation criteria (ECT group) (Ghaziuddin et al. 2004). All subjects were admitted between January 2005 and December 2009 into the inpatient ward of the Child and Adolescent Psychiatry and Psychology Department of Hospital Clinic of Barcelona. Of the 137 patients with schizophrenia spectrum disorder (schizophrenia or schizoaffective disorder, DSMIV criteria) hospitalized in our center during this period, 13 of them (9.49\%) were treated with ECT. Our ECT Committee approved the indication for each of the patients, and written informed consent for ECT was provided by the patients' parents or legal guardians. Lack of response to at least two adequate pharmacotherapeutic trials and/ or intolerance to medication side effects were the most common reason for indication of ECT $(n=7 ; 77.8 \%)$. ECT was considered earlier in other cases when subjects presented with catatonia $(n=2$; $22.2 \%$ ). Statistical analysis was performed with a sample of nine subjects who had completed all clinical and neuropsychological assessments. All subjects received additional pharmacotherapy (including antipsychotics, mood stabilizers, antidepressants, and benzodiazepines) during the acute ECT phase. No negativism, no mutism, and no staring were observed in any of the patients with catatonia when neuropsychological tests were assessed.

Subjects treated with ECT were compared with nine subjects selected from the same 137 treated during this period (44\% men). Schizophrenia $(n=7)$ or schizoaffective disorder $(n=2)$ was diagnosed in these controls, and they were treated with psychiatric drugs but without ECT (NECT group). They were matched for age, socioeconomic status, and PANSS at baseline. Socioeconomic status of the sample was estimated with the Hollingshead Redlich scale (Hollingshead and Redlich 1958).

Exclusion criteria for both groups included (1) presence of another concomitant Axis I disorder at the time of assessment that might account for the psychotic symptoms, including substanceinduced psychotic disorder, post-traumatic stress disorder, or acute stress disorder; (2) Intelligence Quotient (IQ) below 70 with impaired functioning; (3) pervasive developmental disorder; and (4) 
neurological disorders, including history of head trauma with loss of consciousness.

All patients were retrospectively assessed at baseline and at 2year follow-up; and the study was approved by the Ethics Committee of the institution.

\section{Psychopathological assessment}

All subjects were evaluated with the Positive and Negative Syndrome Scale (PANSS) and the Clinical Global ImpressionsImprovement (CGI-I) Scale just before beginning the ECT course and at the 2-year follow-up assessment.

PANSS: This is a 30-item rating scale that aims at assessing the symptom severity of subjects with psychosis. It is subdivided into three subscales-positive, negative, and general psychopathologyand a total score (Kay et al. 1987; Peralta and Cuesta 1994). Each subscale and the total score are all evaluated from 1 to 7 according to the severity of the symptoms. It was always administered by the same psychiatrist (I.B.).

CGI-I scale: This is a clinical scale scored from 1 to 7 that assesses the severity of symptoms. A better level is indicated by lower scores (Guy 1976).

The Neurological Examination Scale (NES) (Buchanan and Heinrichs 1989): This scale assesses neurological soft signs. It comprises 26 items clustered into four subscales: Sensory integration, motor coordination, sequencing of complex motor tasks, and other neurological soft signs. In this study, it was used to assess motor and coordination problems that could affect subjects' performance in neuropsychological tests.

\section{Therapeutic intervention}

All subjects received ECT thrice per week with a constantcurrent, brief-pulse device. Using a systematic protocol, all treatment stimuli were delivered with bifrontotemporal electrode placement administered using a MECTA-SR2 ECT device. Seizure threshold was titrated at the first session, with Stimulus dosing at subsequent treatments of 1.5 times the seizure threshold. Table 1 shows the ECT parameters.

Electroencephalographic and motor seizure manifestations were monitored to ensure adequate duration. Succinylcholine (30$120 \mathrm{mg}$ ), atropine (0-1 mg), and sodium tiopenthal (75-450 mg) or propophol (120-170 mg) were used for anesthesia. The acute ECT course was continued until the acute symptoms remitted or no further improvement was shown over the course of three consecutive sessions.

\section{Neuropsychological assessment}

Cognitive assessment was performed between 4 and 8 weeks after admission when subjects had reached a low in acute psychotic symptoms, before the ECT treatment and at 2-year follow-up, by means of a comprehensive neuropsychological battery designed to assess the following cognitive domains: IQ, working memory, attention, verbal learning and memory, and executive functioning.

To rule out mental retardation, IQ was estimated using the Block Design and Vocabulary subtests of the Wechsler Adult Intelligence Scale-III Revised (WAIS III) (Wechsler 2001) or the Wechsler Intelligence Scale for Children-Revised (Wechsler 1974), depending on the subject's age. Raw scores for each subscale were converted into standard scores with a mean of 10 and a standard deviation of 3 .

Working memory was evaluated using the scores obtained on Digits backward and Letter-Number Sequencing of the WAIS III (Wechsler 2001). The first task requires the subject to say in reverse order the digits that have been read by the examiner. In the letternumber sequencing task, the examiner reads a list of letters and numbers and asks the subject first to say the numbers, from lowest to highest, and then the letters, in alphabetical order.

Attention was assessed by means of the Trail Making Test part A (TMT-A) (Reitan and Wolfson 1985) and Digits forward of the WAIS III (Wechsler 2001). In the first task, the subject is instructed to join with lines the numbers from 1 to 25 on a sheet of paper in the shortest time possible. The time of response was taken into account. In Digits forward, the subject should repeat a series of numbers in the same order as has been read by the examiner.

Verbal memory and learning were evaluated by the Verbal Learning Test-Complutense Spain, the Spanish adaptation of the California Verbal Learning Test, which provides a learning curve and an immediate and delayed memory score (Benedet and Alejandre 1998).

Finally, executive functions were assessed by number of categories, number of mistakes, number of perseverative errors, and number of perseverations on the Wisconsin Card Sorting Test (WCST) (Heaton et al. 1997), the interference part of the Stroop test (Golden 1978), the TMT part B (TMT-B) (Reitan and Wolfson 1985), and the verbal fluency task (FAS) (Lezak 1995). The WCST is a measure of executive function that requires planning strategies and cognitive flexibility to change the use of learned strategies. The interference part of the Stroop test measures the subject's ability to inhibit an automatic predominant response. The FAS is a test of verbal fluency that requires the subjects to generate as many words as possible beginning with a given letter in 60 seconds. In the TMT$\mathrm{B}$, subjects have to join with lines, alternatively, numbers (in increasing order) and letters (in alphabetical order) in the shortest possible time. We used the time to complete the task as a measure of executive function.

\section{Statistical analysis}

To test the normality of the sample distribution, the Kolmogorov-Smirnov test was applied, with the Levene test to assess the

Table 1. Electroconvulsive Therapy Parameters

\begin{tabular}{|c|c|c|c|c|c|c|}
\hline & Mean & Maximum & Minimum & Median & Standard deviation & Valid $N$ sessions \\
\hline Pulse width (ms) & 1 & 2 & 1 & 1 & 0 & 120 \\
\hline Frequency (hertz) & 65 & 80 & 60 & 60 & 8 & 120 \\
\hline Stimulus duration (s) & 0.89 & 1.50 & 0.75 & 1.00 & 0.15 & 120 \\
\hline Current (amps) & 0.63 & 0.80 & 0.60 & 0.60 & 0.07 & 120 \\
\hline Number ECT sessions & 13 & 20 & 7 & 12 & 4 & \\
\hline
\end{tabular}

$\mathrm{ECT}=$ electroconvulsive therapy. 
equality of variances. These two conditions were achieved for both clinical and neuropsychological variables. Categorical sociodemographic variables were compared between the two groups using the chi-square test or $t$-test as appropriate. Between-group comparisons were conducted at first assessment and at 2-year follow-up via multivariate analysis of variance (MANOVA) with variables that differed between groups as covariates. Bonferroni correction for multiple comparisons was applied to avoid the presence of false positives. To assess the change between the first and the second assessment in clinical and neuropsychological variables, a repeated-measures analysis for the General Linear Model was conducted. In neuropsychological assessment, both analyses were conducted according to distinct cognitive domains (Table 2 shows cognitive domains and the associated neuropsychological variables). All analyses were performed using the statistical package SPSS 15.0.

\section{Results}

\section{Socio-demographic characteristics of the sample}

Table 2 shows the gender, age, and socio-economic status of ECT and NECT groups. No significant differences in age, sex, or socio-economic status were found between these two groups.

\section{Treatment characteristics of the sample}

All subjects were receiving pharmacological treatment at first assessment (Table 3). Significant differences were found between groups in the number of unsuccessful medication trials $(t=-2.357$, $p=0.034)$ and dose $(t=2.089, p=0.048)$, both being higher in the ECT group than in the NECT group. Taking into account that the number of failed treatments is interpreted as a severity index, statistical analysis was performed with this variable as a covariate. The mean number of ECT sessions per patient was $12.67 \pm 3.4$ during the acute phase. The mean duration of EEG seizure was $45.8 \pm 17.2$ (minimum $=21 \mathrm{~s}$; maximum $=93 \mathrm{~s}$ ). No subjects presented prolonged seizures.

With regard to adverse events with ECT, only mild and transient side effects were reported during and after ECT sessions, such as headache $(5.9 \%)$ and agitation $(0.5 \%)$. There were no cases of tardive seizures.

At second assessment, two subjects in the ECT group and one patient in the NECT group were not taking medication. All of them reported that they did not want to be on pharmacological treatment.

\section{Comparison between ECT group and no-ECT group at first assessment}

No statistically significant differences were found between the ECT group and NECT group in global severity of symptomatology at baseline (PANSS: $F=0.368, \mathrm{df}=4.13, p=0.826$; CGI: $F=1.276$, $\mathrm{df}=1, p=0.279$ ), nor were significant differences observed in any subscale of NES at baseline (sensory integration: $F=0.170$, $p=0.691$; motor coordination: $F=0.040, p=0.847$; sequencing of complex motor tasks: $F=0.061, p=0.812$; other neurological soft signs: $F=1.200, p=0.305$ ). Table 2 shows the results obtained by each group on PANSS and CGI.

Regarding the cognitive variables, no significant differences were found between the groups at first assessment (Working Memory: $F=1.507, \mathrm{df}=2.15, p=0.261$; Attention: $F=1.506$, $\mathrm{df}=2.15, \quad p=0.261$; Verbal Memory: $F=1.424, \quad \mathrm{df}=3.14$, $p=0.288$; Executive Functions: $F=1.948, \mathrm{df}=8.6, p=0.316$ ). Table 2 shows the cognitive variables in both groups.

\section{Comparison between ECT group and no-ECT group regarding changes at 2-year follow-up}

Regarding changes between the first and the second assessment, both groups showed significant improvement in clinical variables, specifically in the subscales of positive, general, and total score of PANSS $(F=25.504, \mathrm{df}=4.13, p<0.001)$ and CGI $(F=110.278$, $\mathrm{df}=1, p<0.001)$. Moreover, repeated-measures analysis found no significant interaction of time $\times$ group in either PANSS $(F=1.185$, $\mathrm{df}=4.13, p=0.363)$ or CGI $(F=0.405, \mathrm{df}=1, p=0.533)$, which indicates that changes in clinical variables did not differ between the groups (Table 4).

Overall, the analysis of cognitive variables showed higher scores in some attentional $(F=12.753, \mathrm{df}=2.15, p=0.001)$ and executive function variables $(F=4.239, \mathrm{df}=8.6, p=0.048)$. Specifically, in our sample, there was an improvement in digits forward at second assessment in both ECT and NECT groups and in the semantic category of FAS. No significant changes were found in other cognitive measures between the first and the second assessment either in the ECT or in the NECT group (Working Memory: $F=1.138, \quad \mathrm{df}=2.15, \quad p=0.347$; Verbal Memory: $F=1.531$, $\mathrm{df}=4.12, p=0.255$ ). Table 4 shows changes in PANSS, CGI, and neuropsychological variables in both groups. As in the case of clinical variables, the repeated-measures analysis did not reveal significant differences in the interaction time $\times$ group (Working Memory: $F=0.063$, df $=2.15, p=0.939$; Attention: $F=1.124$, $\mathrm{df}=2.15, p=0.351$; Verbal Memory: $F=0.90, \mathrm{df}=4.12, p=0.984$; Executive Functions: $F=2.216, \mathrm{df}=8.6, p=0.174$ ), which means that there were no significant differences between the groups in terms of changes in neuropsychological measures.

\section{Comparison between ECT group and no-ECT group at 2-year follow-up assessment}

At 2-year follow-up, there were no significant differences between groups in any clinical variable (PANSS: $F=2.152, \mathrm{df}=3.14$, $p=0.152$; CGI: $F=2.048, \mathrm{df}=1, p=0.176$ ), and no significant differences were observed between the groups in any NES subscale (sensory integration: $F=0.736, p=0.416$; motor coordination: $F=0.143, p=0.715$; sequencing of complex motor tasks: $F=0.581$, $p=0.468$; other neurological soft signs: $F=3.540, p=0.097$ ).

The comparison of cognitive variables showed no significant differences between ECT and NECT groups in any neuropsychological measure after Bonferroni adjustment (Working Memory: $F=1.653, \mathrm{df}=2.15, p=0.232 ;$ Attention: $F=2.107, \mathrm{df}=2.15$, $p=0.164$; Verbal Memory: $F=0.202$, df $=3.13, p=0.892$; Executive Functions: $F=2.355$, df $=8.9, p=0.156$ ).

Table 2 shows clinical and neuropsychological results of both groups at follow-up assessment.

\section{Discussion}

The main finding of the current study was that, as hypothesized, after 2 years, neuropsychological changes in subjects treated with ECT were similar to those found in subjects not treated with ECT. We found no significant differences in any changes in clinical or neuropsychological variables between the groups during follow-up or at second assessment after 2 years.

Specifically, in our study, both the ECT and NECT groups were matched by age and total PANSS score; therefore, subjects had similar severity of clinical variables at baseline. As was expected, the ECT and NECT groups differed in the number of unsuccessful medication trials, this is due to the fact that the lack of response to at 


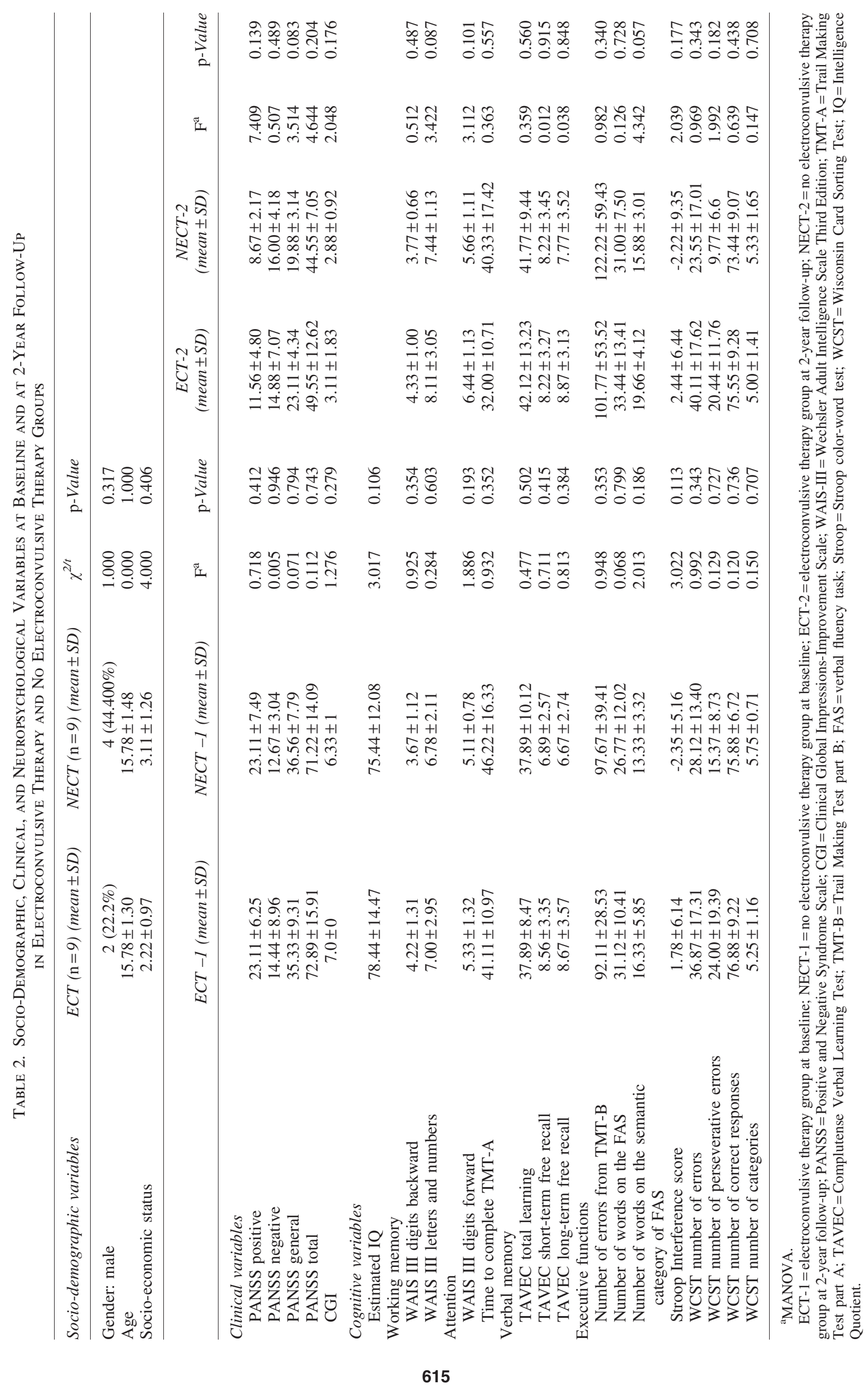


Table 3. Pharmacological Treatment

in Electroconvulsive Therapy (ECT)

and No Electroconvulsive Therapy Groups

\begin{tabular}{|c|c|c|}
\hline Patients & First assessment & Second assessment \\
\hline ECT1 & $\begin{array}{l}\text { Clozapine } 400 \mathrm{mg} / \text { day } \\
\text { Risperidone } 3 \mathrm{mg} / \text { day } \\
\text { Lorazepam } 3 \mathrm{mg} / \text { day }\end{array}$ & Clozapine $275 \mathrm{mg} /$ day \\
\hline ECT2 & $\begin{array}{l}\text { Clozapine } 600 \mathrm{mg} / \text { day } \\
\text { Risperidone } 2 \mathrm{mg} / \text { day }\end{array}$ & $\begin{array}{l}\text { Clozapine } 275 \mathrm{mg} / \text { day } \\
\text { Ziprasidone } 240 \mathrm{mg} / \text { day }\end{array}$ \\
\hline ECT3 & $\begin{array}{l}\text { Trfluoperazine } \\
25 \mathrm{mg} / \text { day }\end{array}$ & $\begin{array}{l}\text { Long acting Risperidone } \\
50 \mathrm{mg} / 14 \text { days }\end{array}$ \\
\hline ECT4 & $\begin{array}{l}\text { Aripiprazole } 15 \mathrm{mg} / \text { day } \\
\text { Lorazepam } 3 \mathrm{mg} / \text { day }\end{array}$ & Without treatment \\
\hline ECT5 & $\begin{array}{l}\text { Risperidone } 4 \mathrm{mg} / \text { day } \\
\text { Clonazepam } 2.5 \mathrm{mg} / \text { day }\end{array}$ & Without treatment \\
\hline ECT6 & $\begin{array}{l}\text { Risperidone } 2 \mathrm{mg} / \mathrm{day} \\
\text { Quetiapine } 1,200 \mathrm{mg} / \text { day }\end{array}$ & Clozapine $500 \mathrm{mg} /$ day \\
\hline ECT7 & $\begin{array}{l}\text { Oxcarbazepine } \\
600 \mathrm{mg} / \text { day } \\
\text { Lithium carbonate } \\
1,600 \mathrm{mg} / \text { day } \\
\text { Quetiapine } \\
1,100 \mathrm{mg} / \text { day }\end{array}$ & $\begin{array}{l}\text { Clozapine } 425 \mathrm{mg} / \text { day } \\
\text { Rsiperidone } 1 \mathrm{mg} / \text { day } \\
\text { Lithium Carbonate } \\
100 \mathrm{mg} / \text { day } \\
\text { Valproic Acid } \\
1,000 \mathrm{mg} / \text { day } \\
\text { Diazepam } 5 \mathrm{mg} / \text { day }\end{array}$ \\
\hline ECT8 & $\begin{array}{l}\text { Lithium Carbonate } \\
1,000 \mathrm{mg} / \text { day } \\
\text { Olanzapine } 20 \mathrm{mg} / \text { day }\end{array}$ & $\begin{array}{l}\text { Clozapine } 300 \mathrm{mg} / \text { day } \\
\text { Lithium Carbonate } \\
1,200 \mathrm{mg} / \text { day }\end{array}$ \\
\hline ЕСТ9 & Quetiapine $100 \mathrm{mg} /$ day & $\begin{array}{l}\text { Quetiapine } 500 \mathrm{mg} / \mathrm{day} \\
\text { Valproic Acid } 800 \mathrm{mg} / \text { day }\end{array}$ \\
\hline No-ECT1 & Risperidone $6 \mathrm{mg} /$ day & $\begin{array}{l}\text { Risperidone } 4 \mathrm{mg} / \text { day } \\
\text { Propranolol } 30 \mathrm{mg} / \text { day }\end{array}$ \\
\hline No-ECT2 & $\begin{array}{l}\text { Risperidone } 3 \mathrm{mg} / \text { day } \\
\text { Diazepam } 5 \mathrm{mg} / \text { day } \\
\text { Biperiden } 4 \mathrm{mg} / \text { day }\end{array}$ & $\begin{array}{l}\text { Risperidone } 1 \mathrm{mg} / \text { day } \\
\text { Diazepam } 10 \mathrm{mg} / \text { day }\end{array}$ \\
\hline No-ECT3 & $\begin{array}{l}\text { Risperidone } 3 \mathrm{mg} / \text { day } \\
\text { Propranolol } 30 \mathrm{mg} / \text { day } \\
\text { Lorazepam } 1 \mathrm{mg} / \text { day } \\
\text { Sertraline } 150 \mathrm{mg} / \text { day }\end{array}$ & $\begin{array}{l}\text { Quetiapine } 300 \mathrm{mg} / \text { day } \\
\text { Valproic Acid 1,000 } \\
\text { mg/day }\end{array}$ \\
\hline No-ECT4 & $\begin{array}{l}\text { Quetiapine } 400 \mathrm{mg} / \text { day } \\
\text { Sertraline } 100 \mathrm{mg} / \text { day }\end{array}$ & $\begin{array}{l}\text { Quetiapine } 1,000 \mathrm{mg} / \text { day } \\
\text { Sertraline } 100 \mathrm{mg} / \text { day }\end{array}$ \\
\hline No-ECT5 & $\begin{array}{l}\text { Risperidone } 4 \mathrm{mg} / \text { day } \\
\text { Sertraline } 100 \mathrm{mg} / \text { day }\end{array}$ & $\begin{array}{l}\text { Long Acting Risperidone } \\
37.5 \mathrm{mg} / 14 \text { days } \\
\text { Risperidone } 3 \mathrm{mg} / \text { day }\end{array}$ \\
\hline No-ECT6 & Risperidone $4 \mathrm{mg} /$ day & Risperidone $3 \mathrm{mg} /$ day \\
\hline No-ECT7 & $\begin{array}{l}\text { Risperidone } 5 \mathrm{mg} / \text { day } \\
\text { Biperiden } 1 \mathrm{mg} / \text { day }\end{array}$ & Risperidone $4 \mathrm{mg} /$ day \\
\hline No-ECT8 & $\begin{array}{l}\text { Risperidone } 2 \mathrm{mg} / \text { day } \\
\text { Lorazepam } 2 \mathrm{mg} / \text { day }\end{array}$ & Without treatment \\
\hline No-ECT9 & Risperidone $6 \mathrm{mg}$ /day & Olanzapine $20 \mathrm{mg} /$ day \\
\hline
\end{tabular}

least two antipsychotics is a recommendation criteria of ECT in the AACAP (Ghaziuddin et al. 2004). Regarding the cognitive variables, our study supports other investigations that have assessed the influence of ECT on cognition and have reported no differences in memory and learning after a few weeks to 7 months of treatment (Weeks et al. 1980; Frith et al. 1983; Smith et al. 2010). Most of these studies do not have a control group against which to compare the baseline results (Calev et al. 1991; Squire and Chace 1996; Smith et al. 2010), and none of them have matched both groups while taking into account the psychopathology that has a clear influence on neuropsychological performance (Basso et al. 1998; Bilder et al. 2000; Fitzgerald et al. 2004; Good et al. 2004). Matching by total PANSS score, our results did not reveal any difference in cognitive variables at first assessment.
At follow-up, our study showed a significant improvement in positive, general, and total score of PANSS in both groups. Previous studies carried out with adolescent samples treated with antipsychotics had showed an improvement in clinical severity of symptoms assessed with the PANSS (Sikich et al. 2008; Arango et al. 2009; Haas et al. 2009; Robb et al. 2010). With ECT and in adolescent patients, Baeza et al. (2010) analyzed a sample of 13 adolescents with schizophrenia syndrome disorder followed-up during 6 months and observed a significant improvement in positive and general PANSS subscales scores. Moreover, Rey and Walter (1997) reviewed studies published about the use of ECT in persons 18 years of age or younger, concluding that the rate of improvement across the studies was $42 \%$ for schizophrenia immediately after the ECT treatment and 10\% 6 months after ECT.

Interestingly, in our study, the repeated-measures analysis found no significant interaction of time $\times$ group; thus, changes in clinical variables seemed to be similar in both groups and were independent of the ECT treatment.

Regarding the cognitive assessment, an improvement in digits forward and the semantic category of FAS was found in both groups 2 years after the ECT treatment. Very few studies have analyzed these cognitive functions. Rami-Gonzalez et al. (2003a) found impairment in verbal fluency. However, the sample of that study was composed of patients with different diagnoses (schizophrenia, depression and bipolar disorder), and the assessment was performed during maintenance ECT. No long-term studies of verbal fluency are found in the literature, and other studies conducted with adolescent samples with severe mood disorders have found no significant differences in attention at long term follow-up (Cohen et al. 2000; Russell et al. 2003).

No significant changes were detected in other neuropsychological variables at 2-year follow-up. These results support other long-term studies that have found no cognitive differences at follow-up (Cohen et al. 2000; Russell et al. 2003). When we analyzed the results with a repeated-measures method, no significant interaction time $\times$ group was found. Thus, the treatment with ECT in our sample had no influence on changes in neuropsychological variables. To our knowledge, no studies in the literature have aimed at analyzing differences in neuropsychological change in adolescent samples with schizophrenia treated with ECT.

Finally, the comparison between the ECT and the NECT groups at 2-year follow-up showed no significant differences between groups in any clinical or neuropsychological variable. Kutcher and Robertson (1995) studied a sample of 22 young patients, aged between 13 and 19, in whom a bipolar disorder was diagnosed and divided them into two groups: 16 who accepted ECT and 6 who refused it and continued with pharmacological treatment. A significant improvement of clinical symptoms was observed in the ECT group. No long-term follow-up studies in children or adolescents in whom schizophrenia was diagnosed and who were treated with ECT have been conducted using the PANSS to assess clinical outcome.

Regarding the cognitive assessment, there are few studies that assess neuropsychological functions in adolescent samples with which to compare our results. Nevertheless, our study supports the research of Cohen et al. (2000) with affective patients. Theirs was the only long-term follow-up study conducted with a sample of adolescent patients treated with ECT, and they found no differences in neuropsychological variables between the ECT group and a psychiatric comparison group.

One of the main limitations of our study is the small sample size, but this is due to the fact that ECT is not a first-choice treatment and is only administrated in specific cases (following the AACAP guidelines). As a result, the study is not powered enough to show rare 
Table 4. Changes in Clinical and Neuropsychological Variables Between First and Second Assessment in Electroconvulsive Therapy and No Electroconvulsive Therapy Groups

\begin{tabular}{|c|c|c|c|c|}
\hline & \multicolumn{2}{|c|}{ Time } & \multicolumn{2}{|c|}{ Time $\times$ group } \\
\hline & $\mathrm{F}^{\mathrm{a}}$ & p-Value & $\mathrm{F}^{\mathrm{a}}$ & p-Value \\
\hline \multicolumn{5}{|l|}{ Clinical variables } \\
\hline PANSS positive & 80.791 & $<0.001$ & 0.997 & 0.333 \\
\hline PANSS negative & 0.711 & 0.412 & 0.415 & 0.528 \\
\hline PANSS general & 30.263 & $<0.001$ & 0.716 & 0.410 \\
\hline PANSS total & 24.671 & $<0.001$ & 0.110 & 0.745 \\
\hline CGI & 110.278 & $<0.001$ & 0.405 & 0.533 \\
\hline \multicolumn{5}{|l|}{ Cognitive variables } \\
\hline \multicolumn{5}{|l|}{ Working memory } \\
\hline WAIS III digits backward & 0.180 & 0.677 & 0.000 & 1.000 \\
\hline WAIS III letter and number & 2.129 & 0.164 & 0.133 & 0.720 \\
\hline \multicolumn{5}{|l|}{ Attention } \\
\hline WAIS III digits forward & 11.688 & 0.004 & 1.299 & 0.271 \\
\hline Time to complete TMT-A & 3.996 & 0.063 & 0.184 & 0.673 \\
\hline \multicolumn{5}{|l|}{ Verbal memory } \\
\hline TAVEC total learning & 4.068 & 0.062 & 0.008 & 0.930 \\
\hline TAVEC short-term free recall & 2.301 & 0.150 & 0.017 & 0.899 \\
\hline TAVEC long-term free recall & 1.369 & 0.260 & 0.004 & 0.952 \\
\hline \multicolumn{5}{|l|}{ Executive functions } \\
\hline Number of errors from TMT-B & 3.004 & 0.107 & 0.651 & 0.434 \\
\hline Number of words on the FAS & 2.938 & 0.110 & 0.180 & 0.679 \\
\hline $\begin{array}{l}\text { Number of words on the semantic } \\
\text { category of FAS }\end{array}$ & 9.229 & 0.010 & 0.012 & 0.914 \\
\hline Stroop interference score & 2.365 & 0.148 & 0.776 & 0.394 \\
\hline WCST number of errors & 1.267 & 0.281 & 1.742 & 0.210 \\
\hline WCST number of perseverative errors & 4.659 & $0.050^{\mathrm{b}}$ & 4.659 & $0.050^{\mathrm{b}}$ \\
\hline WCST number of correct responses & 0.70 & 0.796 & 0.129 & 0.726 \\
\hline WCST number of categories & 0.059 & 0.812 & 0.059 & 0.812 \\
\hline
\end{tabular}

Significant values marked in bold.

${ }^{a}$ MANOVA.

${ }^{\mathrm{b}}$ Repeated measures analysis.

ECT-1 = electroconvulsive therapy group at baseline; NECT-1 = no electroconvulsive therapy group at baseline; ECT-2=electroconvulsive therapy group at 2-year follow-up; NECT-2=no electroconvulsive therapy group at 2-year follow-up; PANSS=Positive and Negative Syndrome Scale; CGI = Clinical Global Impressions-Improvement Scale; WAIS-III = Wechsler Adult Intelligence Scale Third Edition; TMT-A=Trail Making Test part A; TAVEC $=$ Complutense Verbal Learning Test; TMT-B $=$ Trail Making Test part B; FAS = verbal fluency task; Stroop=Stroop color-word test; WCST $=$ Wisconsin Card Sorting Test; IQ = Intelligence Quotient.

incidence events such as those due to secondary effects. Another limitation was that the cognitive assessment was not conducted in a blind fashion, and biographic memory had not been assessed.

Among the strengths of the study, it should be noted that this research has been conducted with two homogeneous samples of adolescents in whom schizophrenia has been diagnosed and matched by age, socio-economic status, and PANSS total score to avoid the influence of severity of clinical symptoms on the neuropsychological assessment. Moreover, all subjects included in the analysis had a long-term follow-up of clinical and cognitive variables that allowed us to assess the long-term influence of ECT on cognitive functions. Indeed, this is the first study to investigate the long-term influence of ECT treatment in a sample of children and adolescents with schizophrenia.

Future research is needed to investigate the long-term cognitive effects of ECT in adolescent patients in whom schizophrenia spectrum disorders have been diagnosed.

\section{Clinical Significance}

The current study shows no significant differences in changes over time in any clinical or neuropsychological variable between an ECT group and a no-ECT group at follow-up. ECT did not seem to have any negative influence on clinical or neuropsychological variables in our sample at 2-year follow-up. Thus, ECT treatment should be taken into serious consideration as a possible treatment in adolescents in whom schizophrenia spectrum disorder is diagnosed, where patients have not responded to at least two adequate pharmacotherapeutic trials. More research is needed to increase knowledge about the longterm effects of ECT on cognition in adolescent subjects.

\section{Disclosures}

Elena de la Serna, Itziar Flamarique, Alexandre Pons, Olga Puig, Susana Andrés-Perpiña, Luisa Lázaro, Juan Miguel Garrido, and Inmaculada Baeza affirm that they have no conflicts of interest.

Prof. M. Bernardo received consulting fees from Bristol-Myers Squibb-Otsuka, Wyeth, Janssen-Cilag.

Dr. J. Castro-Fornieles has had the following relationships that may represent a conflict of interest: Consultant: Eli Lilly and Pfizer; Travel support: Eli Lilly.

\section{Acknowledgments}

This work was supported in part by the Government of Catalonia, Comissionat per Universitats I Recerca del Departament d'Innovació, Universitats I Empresa 2009SGR111. 


\section{References}

American Psychiatric Association: The Practice of ECT: Recommendations for Treatment, Training, and Privileging. A Task Force Report, 2nd ed. Washington, DC; 2001.

Arango C, Robles O, Parellada M, Fraguas D, Ruiz-Sancho A, Medina O, Zabala A, Bombin I, Moreno D: Olanzapine compared to quetiapine in adolescents with a first psychotic episode. Eur Child Adolesc Psychiatry 18:418-428, 2009.

Baeza I, Flamarique I, Garrido JM, Horga G, Pons A, Bernardo M, Morer A, Lázaro ML, Castro-Fornieles J: Clinical experience on ECT in adolescents with schizophrenia spectrum disorders. J Child Adol Psychopharmachol 20:205-209, 2010.

Basso MR, Nasrallah HA, Olson SC, Bornstein RA: Neuropsychological correlates of negative, disorganized and psychotic symptoms in schizophrenia. Schizophr Res 31:99-111, 1998.

Benedet MJ, Alejandre MA: TAVEC, Test de aprendizaje Verbal España-Complutense. Madrid: TEA Ediciones, 1998.

Bilder RM, Goldman RS, Robinson D, Reiter G, Bell L, Bates JA, Pappadopulos E, Willson DF, Alvir JM, Woerner MG, Geisler S, Kane JM, Lieberman JA: Neuropsychology of first-episode schizophrenia: Initial characterization and clinical correlates. Am J Psychiatry 157:549-559, 2000.

Bloch Y, Sobol D, Levkovitz Y, Kron S, Ratzoni G: Reasons for referral for electroconvulsive therapy: A comparison between adolescents and adults. Australas Psychiatry 16:191-194, 2008.

Buchanan RW, Heinrichs DW: The Neurological Evaluation Scale (NES): A structured instrument for the assessment of neurological signs in schizophrenia. Psychiatry Res 27:335-350, 1989.

Calev A, Nigal D, Shapira B, Tubi N, Chazan S, Ben Yehuda Y, Kugelmass S, Lerer B: Early and long-term effects of electroconvulsive therapy and depression on memory and other cognitive functions. J Nerv Ment Dis 179:526-533, 1991.

Calev A, Gaudino EA, Squires NK, Zervas IM, Fink M: ECT and nonmemory cognition: a review. Br J Clin Psychol 34:505-15, 1995.

Cohen D, Taieb O, Flament M, Benoit N, Chevret S, Corcos M, Fossati P, Jeammet P, Allilaire JF, Basquin M: Absence of cognitive impairment at long-term follow-up in adolescents treated with ECT for severe mood disorder. Am J Psychiatry 157:460-462, 2000.

Fitzgerald D, Lucas S, Redoblado MA, Winter V, Brennan J, Anderson J, Harris A: Cognitive functioning in young people with first episode psychosis: relationship to diagnosis and clinical characteristics. Aust N Z J Psychiatry 38:501-510, 2004.

Frith CD, Stevens M, Johnstone EC, Deakin JF, Lawler P, Crow TJ: Effects of ECT and depression on various aspects of memory. Br J Psychiatry 142:610-617, 1983.

Ghaziuddin M, Kutcher S, Knapp P, The Work Group on Quality Issues: Practice parameter for use of electroconvulsive therapy with adolescents. J Am Acad Child Adolesc Psychiatry 43:1521-1539, 2004.

Ghaziuddin N, King CA, Naylor MW, Ghaziuddin M, Chaudhary N, Giordani B, Dequardo JR, Tandon R, Greden J: Electroconvulsive treatment in adolescents with pharmacotherapy-refractory depression. J Child Adolesc Psychopharmacol 6:259-271, 1996.

Ghaziuddin N, Laughrin D, Giordani B: Cognitive side effects of electroconvulsive therapy in adolescents. J Child Adolesc Psychopharmacol 10:269-276, 2000.

Golden CJ: Stroop Color and Word Test. Wood Dale, IL: Stoelting Co., 1978.

Good KP, Rabinowitz J, Whitehorn D, Harvey PD, DeSmedt G, Kopala LC: The relationship of neuropsychological test performance with the PANSS in antipsychotic naive, first-episode psychosis patients. Schizophr Res 68:11-19, 2004.
Guy W: Clinical Global Impression. ECDEU Assessment Manual for Psychopharmacology, Revised National Institute of Mental Health. Rockville, MD., 1976.

Haas M, Unis AS, Armenteros J, Copenhaver MD, Quiroz JA, Kushner SF: A 6-week, randomized, double-blind, placebocontrolled study of the efficacy and safety of risperidone in adolescents with schizophrenia. J Child Adolesc Psychopharmacol 19:611-621, 2009.

Heaton RK, Chelune GJ, Talley JL, Kay G, Curtiss G: Wisconsin Card Sorting Test (WCST). Madrid: TEA Ediciones; 1997.

Hollingshead, A. B and Redlich F.C. Social Class and Mental Illness. Wiley, New York. 1958.

Ingram A, Saling MM, Schweitzer I: Cognitive side effects of brief pulse electroconvulsive therapy: A review. J ECT 24:3-9, 2008.

Johanson A, Gustafson L, Risberg J, Rosen I, Sjobeck M, Silfverskiold P: Long-term follow-up in depressed patients treated with electroconvulsive therapy. J ECT 21:214-220, 2005.

Kay SR, Fiszbein A, Opler LA: The positive and negative syndrome scale (PANSS) for schizophrenia. Schizophr Bull 13:261-276, 1987.

Kutcher S, Robertson HA: Electroconvulsive therapy in treatmentresistant bipolar youth. J Child Adolesc Psychopharmacol 5:167175,1995

Lezak MD: Neuropsychological Assessment, 3rd ed. New York: Oxford University Press, 1995, pp. 333-686.

Lisanby SH, Maddox JH, Prudic J, Devanand DP, Sackeim HA: The effects of electroconvulsive therapy on memory of autobiographical and public events. Arch Gen Psychiatry 57:581-590, 2000.

MacQueen G, Parkin C, Marriott M, Begin H, Hasey G: The longterm impact of treatment with electroconvulsive therapy on discrete memory systems in patients with bipolar disorder. J Psychiatry Neurosci 32:241-249, 2007.

Moise FN, Petrides G: Case study: Electroconvulsive therapy in adolescents. J Am Acad Child Adolesc Psychiatry 35:312-318, 1996.

Peralta V, Cuesta MJ: Psychometric properties of the positive and negative syndrome scale (PANSS) in schizophrenia. Psychiatry Res 53:31-40, 1994.

Rami L, Bernardo M, Boget T, Ferrer J, Portella MJ, Gil-Verona JA, Salamero M: Cognitive status of psychiatric patients under maintenance electroconvulsive therapy: a one-year longitudinal study. J Neuropsychiatry Clin Neurosci 16:465-471, 2004.

Rami-Gonzalez L, Bernardo M, Boget T, Salamero M, Gil-Verona JA, Junque C: Subtypes of memory dysfunction associated with ECT: Characteristics and neurobiological bases. J ECT 17:129-135, 2001.

Rami-Gonzalez L, Salamero M, Boget T, Catalan R, Ferrer J, Bernardo M: Pattern of cognitive dysfunction in depressive patients during maintenance electroconvulsive therapy. Psychol Med 33: 345-350, 2003a.

Rami-Gonzalez L, Bernardo M, Portella MJ, Goti J, Gil-Verona JA, Salamero M: Assessment of frontal functions in psychiatric patients during maintenance electroconvulsive therapy. Actas Esp Psiquiatr 31:69-72, 2003b.

Reitan RM, Wolfson D: The Halstead-Reitan Neuropsychological Test Battery. Tucson AZ: Neuropsychology Press, 1985.

Rey JM, Walter G: Half a century of ECT use in young people. Am J Psychiatry 154:595-602, 1997.

Robb AS, Carson WH, Nyilas M, Ali M, Forbes RA, Iwamoto T, Assuncao-Talbott S, Whitehead R, Pikalov A: Changes in positive and negative syndrome scale-derived hostility factor in adolescents with schizophrenia treated with aripiprazole: post hoc analysis of randomized clinical trial data. J Child Adolesc Psychopharmacol 20:33-38, 2010.

Russell JC, Rasmussen KG, O'Connor MK, Copeman CA, Ryan DA, Rummans TA: Long-term maintenance ECT: A retrospective review of efficacy and cognitive outcome. J ECT 19:4-9, 2003. 
Sackeim HA, Prudic J, Devanand DP, Nobler MS, Lisanby SH, Peyser S, Fitzsimons L, Moody BJ, Clark J: A prospective, randomized, double-blind comparison of bilateral and right unilateral electroconvulsive therapy at different stimulus intensities. Arch Gen Psychiatry 57:425-34, 2000.

Sackeim HA, Prudic J, Nobler MS, Fitzsimons L, Lisanby SH, Payne N, Berman RM, Brakemeier EL, Perera T, Devanand DP: Effects of pulse width and electrode placement on the efficacy and cognitive effects of electroconvulsive therapy. Brain Stimul 1:71-83, 2008.

Sikich L, Frazier JA, McClellan J, Findling RL, Vitiello B, Ritz L, Ambler D, Puglia M, Maloney AE, Michael E, De Jong S, Slifka K, Noyes N, Hlastala S, Pierson L, McNamara NK, Delporto-Bedoya D, Anderson R, Hamer RM, Lieberman JA: Double-blind comparison of first- and second-generation antipsychotics in early-onset schizophrenia and schizo-affective disorder: Findings from the treatment of early-onset schizophrenia spectrum disorders (TEOSS) study. Am J Psychiatry 165:1420-1431, 2008.

Smith GE, Rasmussen KG, Cullum CM, Felmlee-Devine MD, Petrides G, Rummans TA, Husain MM, Mueller M, Bernstein HJ, Knapp RG, O'Connor MK, Fink M, Sampson S, Bailine SH, Kellner $\mathrm{CH}$ : A randomized controlled trial comparing the memory effects of continuation electroconvulsive therapy versus continuation pharmacotherapy: Results from the Consortium for Research in ECT (CORE) study. J Clin Psychiatry 71:185-193, 2010.

Squire LR: ECT and memory loss. Am J Psychiatry 134:997-1001, 1977.

Squire LR, Chace PM: Memory functions six to nine months after electroconvulsive therapy. 1975. Convuls Ther 12:239-256, 1996.

Steif BL, Sackeim HA, Portnoy S, Decina P, Malitz S: Effects of depression and ECT on anterograde memory. Biol Psychiatry 21:921-930, 1986.
Taieb O, Flament MF, Chevret S, Jeammet P, Allilaire JF, Mazet P, Cohen D: Clinical relevance of electroconvulsive therapy (ECT) in adolescents with severe mood disorder: Evidence from a follow-up study. Eur Psychiatry 17:206-212, 2002.

Tsourtos G, Spong J, Stough C: The effects of electro-convulsive therapy on the speed of information processing in major depression. J Affect Disord 103:263-266, 2007.

Vothknecht S, Kho KH, van Schaick HW, Zwinderman AH, Middelkoop H, Blansjaar BA: Effects of maintenance electroconvulsive therapy on cognitive functions. J ECT 19:151-157, 2003.

Wechsler D: WAIS-III Wechsler Intelligence Scale for Adults. Madrid: TEA Ediciones, 2001.

Wechsler D: Wechsler Intelligence Scale for Children-Revised (WISC-R). Madrid: TEA Ediciones, 1974.

Weeks D, Freeman CP, Kendell RE: ECT: III: Enduring cognitive deficits? Br J Psychiatry 137:26-37, 1980.

Zervas IM, Calev A, Jandorf L, Schwartz J, Gaudino E, Tubi N, Lerer B, Shapira B: Age-dependent effects of electroconvulsive therapy on memory. Convuls Ther 9:39-42, 1993.

Address correspondence to:

Elena de la Serna, Ph.D.

Department of Child and Adolescent Psychiatry and Psychology Institut Clinic de Neurociències

Hospital Clínic Universitari

C/Villarroel, 170

Barcelona 08036

Spain

E-mail: eserna@clinic.ub.es 

Reproduced with permission of the copyright owner. Further reproduction prohibited without permission. 